\title{
The Application of Information Technology in the Library Knowledge Management
}

\author{
Zongying $\mathrm{SHU}^{1, \text { a * }}$ \\ ${ }^{1}$ Library, Chongqing University of Education, Chongqing, 400067, China \\ aszy17@163.com \\ ${ }^{*}$ Corresponding author
}

Keywords: Knowledge Management ; Library; Information Resources; Cataloging Standards

\begin{abstract}
This paper provides comprehensive coverage of the theories research connected with the provision and management of electronic resources in libraries to show us with comprehensive coverage of the core topics related to electronic resource methods. Digital library is an extension of traditional library functions, it is information collection, conversion, to describe, and the computer can handle in the form of digital information collection and storage of digital information network to intelligent information retrieval methods and unified search interface to use Advanced information processing technology and the Internet, providing a variety of languages compatible with the long-range multi-media digital information services. With the rapid development of computer technology, communication technology and network technology, the construction of information expressway and use have offered the environment and condition for development of extensive information system, library system. The information resources in libraries are getting more and more rich, the digitized tendency is getting more and more obvious . Some technique such as the information resource integration technology, electronic resource management and cataloging standard technique have enhanced day by day. In order to better serve for the reader and cause readers to refer to the more literature resources in the shortest time, the research of the library information resource technique should pay attention to library pursuers.
\end{abstract}

\section{Introduction}

Whether the electronic resource comes from a commercial publisher or a local digitization effort, this trend is also rapidly changing library operational and organizational practices. These developments, coupled with the new expectations of the Internet-savvy user, affected all types of libraries who had to rapidly shift from print-based to electronic resources. Along with the increase in electronic resource acquisitions, librarians have had to quickly adapt and address an ever complex set of new challenges and changes related to: workflow management and planning; selection and acquisition procedures; copyright and license negotiation; cataloging practices; public access interfaces; and utilization of usage statistics. Libraries must now come to terms with how to better evaluate, acquire, store, and manage this wealth of electronic resources ${ }^{[1][2]}$. The proliferation of electronic resource management systems (ERMS) presents an additional problem for libraries, that must now develop in-house resource management solutions or acquire one of a myriad of emerging turn-key solutions and implement them in an evolving organizational setting.

Broadly, activities and tools used by a library to manage their investment in electronic products. More finely, electronic resources management refers to several specific management areas (acquisitions, access, workflow, trial, statistics, costs, etc.) that have been defined by the Digital Library Federation.

\section{Library services model}

During the past decade, there has been phenomenal growth in the number of electronic resources including electronic journal packages and full text aggregations acquired by libraries. University Libraries projected will become more digital Though this prediction has yet to come to pass, the 
Association of Research Libraries (ARL) expenditure trend data (Association of Research Libraries, 2002) showed that academic libraries are "in the midst of a profound shift toward reliance on electronic resources, and this reliance seems to have deepened just within the last year or two as libraries have shed paper journal subscriptions to help pay for online access.” Since providing access to electronic resources have become such a major part of the library services, it was crucial for libraries to tackle these new challenges head on.

Libraries provide their users with different ways of accessing its electronic information resources, such as the ILS, a library developed Web site that include listings of available e-resources and a meta search system (sometimes referred to as federated search). Library users may start an e-resource research session from any of these systems. Many libraries also provide access through other nonlibrary systems, such as the Learning Management System (LMS), an enterprise portal, and so forth. Many of these systems perform authentication. Depending on how the user starts the research, the user may have different experiences in terms of authentication. These access points should briefly discussed here.

Usually, when a patron tries to access a resource that is part of the library's local collection and restricted, such as an item in an electronic reserves collection, the ILS itself will authenticate the patron. In other words, the ILS will use its own internal authentication mechanism to authenticate the user.

However, if the resource resides outside the ILS, such as an electronic journal, the ILS will simply redirect the user to the resource itself, or to another authenticator, such as a proxy server, which in turn authenticates the user. In this case, the ILS delegates the authentication to another authenticator $^{[3]}$. Some ILS vendors provide a proxy server as an add-on module that is integrated to the ILS (e.g., Web Access Management from Innovative Interfaces, Inc.). These modules authenticate patrons using the ILS's internal patron database.

\section{New media in libraries}

Libraries are standard-bound institutions, applying rigorous rules to cataloging, classification, coding, indexing, and authority work. The international descriptive cataloging standard, the Anglo-American Cataloging Rules, 2nd edition,(AACR2) (2002), for example, includes rules governing naming library print, audiovisual, and electronic media in the title statement. Even when no title exists, there are rules for compiling one. But standards are never comprehensive, nor can they be. There are always exceptions that do not fit the rule. AACR2 uses language of sufficient generality and vagueness to leave catalogers with considerable interpretive or subjective latitude.

This flexibility works fairly well for print and microfilm, since these "old" media are relatively stable in their presentation, making exceptions finite. This flexibility becomes a liability in the case of electronic resources, where presentation is far from stable and where name changes occur frequently. The standard makers cannot keep up with the evolving nature of "new" media in libraries. As a result, a small cottage industry of additional guidelines and interpretations flourish between standards editions. The continually updated, Library of Congress Rule Interpretations(LCRI) (Office of Descriptive Cataloging Policy, Library of Congress, 1989), for example, amplifies and explains existing rules and adds new ones for areas not covered in AACR2. CONSER(Cooperative Online Serials) is an international online serials cataloging program run by the Library of Congress. Module 31 of the CONSER Cataloging Manual (2006) is a supplemental standard specifically geared to deal with the complexities of cataloging online serials. Module 31 only applies to individual electronic journals and newsletters, that is, to serials in the narrows sense, and not to databases. While such guides assist catalogers in interpreting standards, they also sanction subjective interpretation and make exceptional applications quasi-standards.

When it comes to the ever-changing field of electronic resources with their multiple sources for description information, the cataloger is often at sea, and must extrapolate from standards applicable to print media or invent totally new approaches for emerging realities. Since its first appearance, AACR2 has gone through a series of revisions and updates. Yet it still lags behind the real world of electronic resources. A so-called third edition, AACR3, is now under development. This potentially new 
backward-compatible standard is intended to address some of the most awkward problems AACR2 has in application to electronic resources (Weiss, 2006).

Library systems in general become corrupted over time. Standards are applied differently from institution to institution, from one individual to another, and over the life of a system. As new standards and local administrative policies are implemented and displace old standards and policies, catalogs demonstrate a hodgepodge of different standards and policy applications ${ }^{[4]}$. This is true even in the relatively short time that electronic resources have been widely accessible in libraries A spot check of library catalogs reveals that in many, electronic resource titles receive different treatment, for example, for capitalization, that is only explainable as a change in policy or interpretation. The inconsistency remains embedded in the catalog record unchanged perhaps for the life of the catalog.

Cataloging standards and guidelines can not be systematically applied in the creation of metadata for electronic resource A to Z lists or ERM records, where their weaknesses in relation to electronic resources are even more apparent than in the catalog.

\section{Electronic resources for library services}

This explosion of electronic resources has created a new workload requirement: management. Management of electronic resources is a time-consuming and, at times, a difficult process. Although the management of electronic resources is often seen as a strictly technical services endeavor, it should been considered a multi-faceted process requiring all areas of the library. Bergman (2005) found that the workflow surrounding managing electronic resources does not fit into a neat package belonging entirely to the realm of technical services librarians or public services librarians. The workflow currently in place at JSU is just such a practice. The management of electronic resource workflow is a collaborative effort between public service and technical service librarians. At JSU, the public services librarians collaborate with the technical services librarians in order to provide a substantial collection of electronic resources and to make this collection available to the users as quickly as possible. It is this collaboration that makes the workflow inimitable. The collaborative effort begins with the review process, both trial reviews of databases, e-journals, and so forth and reviews of freely accessible materials such as Websites, extends through the acquisitions, administration, cataloging/bibliographic control, marketing, training, and ends with the assessment of the resources. No matter what workflow a library uses for electronic resources, good communication at each stage in the process is paramount since there is no physical trail of where the item is in the workflow until it gets to the bibliographic control stage.

Despite the physical division between "technical" and "public" services in the library, managing electronic resources is one of many shared responsibilities. The mission of the HCL is to provide information services and bibliographic resources to support the scholarly and informational needs of the university community. To meet user expectations better, the public service librarians' responsibilities at JSU have evolved to include four major professional areas ${ }^{[5]}$. All areas are both interchangeable with and interconnected to one another. For example, effective reference is impossible without a sound collection and vice versa. The four areas are: (1) reference, (2)collection management and development of their respective subject areas, (3) instruction, and (4)liaison activities. Liaison activities include a structured liaison partnership between university teaching faculty and library faculty which includes appointment letters, a list serve, and formal communications between librarians and departmental liaisons. An informal relationship between librarians and teaching faculty is also encouraged and expected as part of their liaison activities job responsibilities.

Additionally, these four professional areas for the public service librarians are dependent on and mirror the four technical services professional responsibilities to: (1) Provide the correct bibliographic data and access points; (2) order, pay, and process the materials requested; (3)deliver or notify the public services librarians of new information sources; and (4) process nonlibrary faculty request and inform them of new information sources. 


\section{Conclusion}

Electronic resources may take many forms, from e-books or journals to full-text resources from aggregators, or index/abstract databases from publishers. The way in which electronic resources are managed is becoming more distinct from print with new approaches to planning, tasks, workflow and communication. The planning process encompasses policy-making, budgeting, and staffing. Tasks may include things like setting up trials, license negotiation, authentication, troubleshooting, evaluation, and renewal. Workflow covers the entire process from initial product consideration, making the resource available to patrons, to renewal or cancellation. Communication includes a variety of interactions from local administrators to vendors, IT staff, public service personnel, and users. So it is important to research the topics related to electronic resource management of library, and we should pay more attention in order to promote library digital level.

\section{Acknowledgement}

In this paper, the research was sponsored by the Chongqing science and technology commission project No.cstc2015jcyjA30006

\section{References}

[1] Anderson, R, Buying and contracting for resources and services: A how-to-do-it manual for librarians. New York: Neal-Schuman Publishers.2003.

[2] Lee, S. D., \& Boyle, F.Building an electronic resource collection: A practical guide. London:Facet Publishing, 2004.

[3] White, A. C. E-metrics for library and information professionals : How to use data for managing and evaluating electronic resource. New York: Neal-Schuman Publishers. 2006.

[4] Kichuk, D, Library space study. Unpublished internal report, University of Saskatchewan Library, Saskatoon. 2000, pp. 148-170.

[5] Collantes, L. Degree of agreement in naming objects and concepts for information retrieval. Journal of the American Society for Information Science, 1995,46(2), 116-132. 